\title{
Internet of Things (IoT) on Fostering Meaningful Science Learning: A Literature Review
}

\author{
A Hujatulatif ${ }^{1}, \mathrm{~J} \mathrm{Ikhsan}^{2}$ and I N Khoiriza ${ }^{3}$ \\ \{adhahujatulatif.2020@student.uny.ac.id\} \\ Science Education, Universitas Negeri Yogyakarta, Sleman Yogyakarta ${ }^{1,3}$, Chemistry Education, \\ Universitas Negeri Yogyakarta, Sleman Yogyakarta ${ }^{2}$
}

\begin{abstract}
Technological advances in this era are developing very rapidly, including 5G technology. This has led to the development of IoT which can be used in various fields including in education. Saveral researchers have developed IoT in education management or in learning. The purpose of this study is to provide an overview of the potential for IoT in science education as a preliminary study of our present research in use of IoT to improve the quality of meaningful science learning. This research is a literature review research. The review was carried out by analyzing articles in the Scopus, ERIC and Google scholar citation databases. In this case, IoT has been identified by several studies as having very useful potential to support more comprehensive learning activities. Based on the results of this literature review, IoT can be new breakthrough that has the potential to improve meaningful in science learning.
\end{abstract}

Keyword : Internet of Things (IoT), Meaningful Learning, Science Education, Science Learning

\section{Introduction}

Science is the systematic study of the structure and function of the natural world, including physical and biological characteristics. It is a field of philosophy concerned with the study of nature, processes, and interactions among diverse occurrences, with the ultimate objective of science being the discovery of the simplest general principles capable of explaining nature's vast complexity. These concepts may be utilized to learn more about the natural world and create predictions about what will happen in the future.

Theoretical thermodynamics may be used, for example, to forecast the rate at which temperature changes in a specific area. Science is a collection of interrelated ideas that emerge from experiments and observations and are valuable in future experiments and observations. It is known as the scientific method, which is a matured style of thinking. [1] Science is a technique of learning about natural events that has largely supplanted the impact of less objective approaches and worldviews [1]. Belief systems based on religion, morality, and aesthetics, for example, are important alternatives to science in all societies. These belief systems are largely aimed towards goals other than science, such as discovering purpose beyond simple existence, understanding how individuals are taught to act, and appreciating the worth of creative expression. Throughout history, numerous scientists have employed the scientific method to uncover new information and understanding [2]. 
The scientific method to learning involves five learning experiences in order to gain knowledge in science. Observation, questioning, acquiring knowledge, reasoning/associating, and communicating are all part of it. Its main objective is for pupils to understand the nature of studying science. Thus, children can discover their own concepts that are explored extensively, meaningfully, authentically, and actively in the process of studying science in school [1]. We are concentrating on encouraging one of the processes of scientific learning, namely meaningful learning, in this study. This indicates that the pupils will be able to comprehend and apply what they have learned in a meaningful way. This article explore an overview how these meaningful can be fostered to science learning.

The construction of meaningful learning was first popularized by Ausubel, who stated that meaningful learning is what happens when someone learns about new experiences and relates them to what that person already knows. Therefore, when someone experiences meaningful learning, it will imply a longer retention than memorizing. This occurs when humans connect new ideas or concepts with familiar, pre-existing concepts. Then with that comes the changes made in our cognitive structure, existing concepts are modified and perhaps new links are produced more comprehensively. This is something important to develop in learning because it allows learning to be contextual, results in greater retention and facilitates transfer to other real situations [3].

A researcher called Jonassen and colleagues used a constructivist viewpoint on the use of technology in schools to build technology-based activities that might enhance meaningful learning in the classroom in order to further improve meaningful learning. Then define meaningful learning as instances in which students actively participate in the creation of meaning, and they break this concept down into five qualities. Active (manipulative, observant), Constructive (articulative, reflective), Intentional (reflective, regulatory), Authentic (complex, contextualised), and Cooperative were the five characteristics (collaborative, conversational). They recommended that instructors begin to think of technologies as learning tools that students learn with rather than from, and that this approach reflects the manner in which technology is likely to be used by informal learners who are not restricted by externally imposed formal learning frameworks. As a result, the characteristics of meaningful learning proposed by Jonassen et al. were utilized to assess the learning that took place in their blog. A project is significant if it satisfies two requirements, according to Larmer and Mergendoller. First, students must consider the job as personally meaningful, an essential assignment, and one that they desire to do with the greatest amount of effort possible [4]. Second, programs that contribute to educational objectives [5].

Based on the above, to improve quality science learning, a meaningful science learning must be developed. Jonassen has revealed that this can be done with the help of technology. Today's technology continues to develop very rapidly, so the variety of technologies that can be used to help meet the criteria for fostering meaningful science learning is increasingly varied too. One of the technology today is the Internet of thing. The Internet of Things (IoT) is a network of physical and interconnected items that may be used to monitor and exploit information. The internet has evolved into a network of devices of all kinds and sizes, including automobiles, smart phones, home appliances, toys, cameras, medical equipment and industrial systems, animals, people, buildings, and wearables, where everything is linked. To accomplish intelligent rearrangement, positioning, tracking, security, and control, all tools and information may be exchanged and shared based on defined protocols, including personal real-time online monitoring, online augmentation, process management, and administration. The Internet of Things (IoT) is the latest Internet revolution. 
Because they can transmit information about themselves in anything, IoT systems, individuals, or objects can make themselves automatically identifiable as information or information providers and develop intelligence by making or activating context-related judgments [6]. As a result, there is an idea to utilize IoT technology to encourage meaningful science learning since the potential IoT allows physical items to connect and interact as well as to equip them with intelligence to analyze particular information. This data may then be utilized to create decisions that are both socially and technologically valuable. It is very appropriate if IoT is used in science learning as a sample model of IoT can be seen at figure 1. It is based on previous developments regarding microcontrollers, directional mirrors, frames, and other hardware, a smart mirror, as a mirror display screen, offers a type that is safer, more convenient, faster, more precise, and smarter, and is information-based. As a result, it is hoped that this tool would assist students in becoming more creative, inventive, and enthusiastic about science[7][8][9].

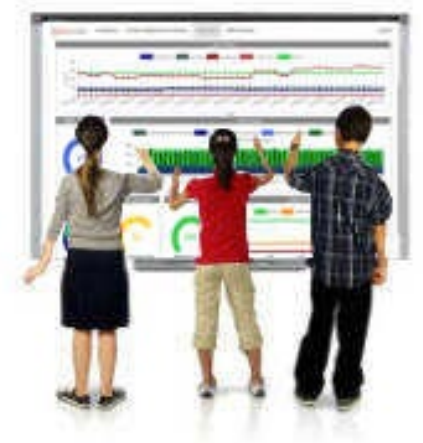

Figure 1. Sample model of IoT

\section{Method}

\subsection{Literature review : Internet of Things (IoT) on Fostering Meaningful Science Learning}

This research began by looking for articles from three online search engine citation sources database, namely Scopus, Education Resources Information Center (ERIC) and Google Schoolar, which are then displayed as follows:

Table 1. List number of articles found

\begin{tabular}{lccc}
\hline \multirow{2}{*}{ Keywords } & \multicolumn{3}{c}{ Number of Article Found } \\
\cline { 2 - 4 } & ERIC & GS & Scopus (Elsivier) \\
\hline Internet Of Things (IoT) & 94 & 407,000 & 42,346 \\
Meaningful Learning & 5,430 & $1,110,000$ & 95,161 \\
Science education & 5,1910 & $1,390,000$ & 446,172 \\
Science learning & 3,0695 & $1,270,000$ & 308,683 \\
\hline
\end{tabular}

Based on this table, it is known that Google Schoolar has a much higher number of search results than ERIC and Scopus. However, when viewed from the specifications and quality of the articles found, Eric has a high degree of accuracy because in ERIC it focuses on articles with 
the theme of Education only. On searches, on the Scopus, Education Resources Information Center search engine and Google Schoolar using the following keywords: Internet of Thing, meaningful learning, science education and science learning found around $\mathrm{xxxx}$ articles from Scopus, ERIC xxxxx and xxx articles from Google Scholar. However, for internet of things (IoT) on fostering meaningful science has never been done, so it will be a very big opportunity for further researchers to continue research by this topic.

\subsection{Literature review Internet of Thing}

Today, the rapid progress in the world of technologies that have reached nearly every human being on the planet, $5 \mathrm{G}$ connections enable close and long-distance communication for everyone and everything. Now, anybody, everywhere, and at any time may access information and communicate using this technology. The Internet of Things is one of these technologies (IoT). The Internet of Things (IoT) is a future version of the Internet that will allow machineto-machine (M2M) learning.

For both software and hardware applications, the long-term goal of the IoT curtain is to provide independent communication, secure power, and enable the flow of genuine information for everyone on the planet. The Internet of Things (IoT) establishes links between real-world physical causes and the virtual world [10]. The assistance of numerous helper apps, the means of Internet contact have advanced very fast, linking zillions of other things, both good and bad information, all over the world, and some of these objects from varied processing capacities, sizes, calculations, and pressures. These networked items contain data that can be gathered, evaluated, and utilized to start activities through particular instructions, giving a great deal of intelligence for planning, management, and accurate decision-making based on sophisticated, real-time analytical processes. This figure 2 explain the general of IoT as follow:

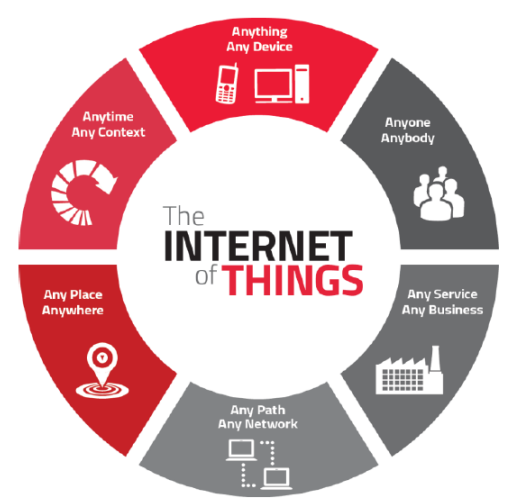

Fig 2. Internet of thing in general

\section{Result and Discussion}

\subsection{Internet of Thing in Science Education}

IoT has been recognized as a new technology that will have a significant impact on a variety of areas, including business, health care, transportation, education, and even scientific future 
prediction [11]. Internet connectivity is rapidly expanding and is already widely utilized in our daily lives; there are presently 5 billion "smart" linked things in use, with that number expected to rise to 50 billion by 2020 .

The Internet of Things (IoT) will continue to expand as internet access speeds improve. Even during the Covid-19 epidemic, inventions such as the $5 \mathrm{G}$ connection have a significant impact, since everyone is obliged to connect to the internet because to a lack of physical distance. This has also caused individuals to become increasingly connected to the internet, causing all internet providers across the world to boost their internet speed capabilities in order to accommodate the massive amounts of data flowing through the internet network.

The Internet of Things (IoT) paradigm may be defined as the numerous items that surround us and are connected to the internet in some way. To put it another way, instruments in the environment like as televisions, lights, vehicles, telephones, and even plants may be connected with smart sensors and communicate and interact with one another via wireless networks or the internet at any time and place to create specific information. The Internet of Things is born from the integration of mobile devices and sensors in smart objects, ushering in a new age in education.

Furthermore, there is a reference saying that researchers performed study in the science inquiry system of primary school pupils in Hong Kong by constructing mobile or cellular devices. Researchers found that mobile technology aids pupils' scientific research and helps them build critical thinking abilities. Students are permitted to utilize tablet computers and commercial science inquiry programs on the shelf in the learning they generate, according to reports. The findings suggest that combining mobile learning with inquiry-based learning environments may be done successfully [13].

Recent study in the United Kingdom has demonstrated how the Internet of Things may improve the quality of science and other subjects such as technology and geography. This project assists students and instructors in measuring, sharing data, and gaining a better knowledge of their surroundings in a fun yet educational way, with the ultimate objective of developing the next generation of lesson plans. Following implementation, the project discovered that the IoT could provide new learning experiences by allowing students and teachers to delve deeper into the data they generated, stimulating open-ended classroom discussion and discovery, and shifting time in the classroom from setup to higher-level learning activities.

However, the researchers discovered that when students gathered data from weather sensors, they were less interested and driven. So, if there are people who want to pursue this research in the future, they must focus on how to address the students' lack of desire. Even yet, some of the items they discovered may still be utilized as references to help students understand science [12]. Smart objects will be utilized at universities in 2017, according to a previous reference, and this has now happened and will soon be widely used in K-12. In the future, educators and technology developers will have a huge problem in finding new ways of learning and ensuring that new learning methodologies based on their utilization are acceptable for students in the twenty-first century. Something that has a lot of promise for academics to work on next, because it will obviously have a big influence on the quality of learning.

\subsection{Internet of Thing on Fostering Meaningful Science Learning}

After looking at the various references that have been reviewed above, as we have previously stated that we have the idea of using IoT technology to foster meaningful learning in science learning because of the potential for IoT that we have discussed previously which allows 
objects in this case are media learning, students, teachers or facilitators and tangible science learning objects can connect and communicate and equip them with intelligence to process specific information. Next, we will develop a special IOT system in science learning. A subject for learning about living and non-living things by watching real-time sensory data and videos or photos of growing peanuts (living things) and rocks (non-living things) using the IOT system we created.

Table 2. Adapted Rubric for Identifying the Attributes of Meaningful Learning

\begin{tabular}{|c|c|}
\hline Attibuttes & Indicators \\
\hline Intentional & 1. Students choose their own learning objectives. \\
\hline Learning & $\begin{array}{l}\text { 2. Students create knowledge using different methods } \\
\text { such as timelines, graphs, mind maps, and idea maps. }\end{array}$ \\
\hline \multirow[t]{3}{*}{$\begin{array}{l}\text { Constructive } \\
\text { Learning }\end{array}$} & $\begin{array}{l}\text { 1. Students are often thinking about what they're } \\
\text { studying. }\end{array}$ \\
\hline & $\begin{array}{l}\text { 2. Students may critically and constructively examine, } \\
\text { evaluate, and criticize the ideas of their classmates. }\end{array}$ \\
\hline & $\begin{array}{l}\text { 3. Students are allowed to reply to questions posed by the } \\
\text { instructor. }\end{array}$ \\
\hline
\end{tabular}

The IOT device produced for this project will be the instrument utilized in the following investigation. The information was gathered via the students' reflection reports and messages on their learning experiences, which were stored on the gadget. The qualitative data will be analyzed using a rubric modified by Mohamed Amin and Amelia from Jonassen's rubric, which is based on four significant learning characteristics (see Table 2). In this study, the modified version of the rubric was used since the five qualities of meaningful learning matched the study's requirements.

\section{Conclusion}

This study offers a literature review research project based on the Internet of Things (IoT) paradigm in scientific learning, which has the potential to provide significant benefits to students. The growing popularity of the Internet of Things has permitted the creation of an innovative, relevant educational learning tool for students studying science. It is envisaged that IOT-based learning would enable students to experience customized, rich, and interactive learning whenever and wherever they require it. As a result, collaborative involvement outside of the classroom can make the learning process more dynamic.

We are now evaluating our IOT ideas' system before conducting a deployment study of the prototype in Indonesian schools. The research will look into how students engage with the IOT system and how effectively it promotes scientific experiment learning. The purpose of the observation will be to learn how kids interact with their peers, teachers, and the tools used to perform IOT systems. Students will learn about living and non-living things by using the IOT system to see real-time sensory data, videos, or photos of growing beans (living things) and rocks (non-living things). To measure students' involvement in learning and the usability of the IOT system, questionnaires and interview sessions will be used. The gadgets of the Internet of Things will also be evaluated for dependability, robustness, and user-friendliness. When the 
data collection is complete, the users' attitudes, views, engagement, and learning efficacy in relation to IOT for encouraging meaningful learning in scientific learning will be examined. This product will then be used to produce a final generic design framework, guidelines, and applications.

\section{References}

[1] Firdausy B A and Prasetyo Z K 2020 J. Phys. Conf. Ser. 1440

[2] Freedman bill 2000 Mar. Pollut. Bull. 14112

[3] Vallori A B 2014 J. Educ. Hum. Dev.

[4] Jonassen D.H. S J 2004 Modeling for Meaningful Learning (Springer, Dordrecht)

[5] John, Larmer; John R. M 2010 Seven Essentials for Project-Based Learning vol 68, ed E in C Anthony Rebora (Educational Leadership)

[6] Vermesan, Ovidiu;Friess P 2012 Internet of things vol 25, ed MARINA RUGGIERI (Denmark: River Publisher)

[7] Widianto M H, Ranny, Thejowahyono N F and Handoyo S B 2020 Int. J. Emerg. Trends Eng. Res. 8

[8] Yusrizal 2016 J. Teknol. Inf. dan Komun. Inf. dan Komun. 5 13-28

[9] Murphy M 2016 Aust. Counc. Educ. Res. 1-33

[10] Xi W and Patton E W

[11] Wang Y 2010 Int. Conf. Comput. Appl. Syst. Model. 13 587-90

[12] Joyce C, Pham H, Stanton Fraser D, Payne S, Crellin D and McDougall S 2014 289-92

[13] Song Y 2014 Comput. Educ. 74 50-60 